\title{
A AGENDA ECOLÓGICA E A PALAVRA DE DEUS: O QUE AMBAS TÊM A NOS DIZER?
}

\section{ARTIGO ORIGINAL}

ASSIS, Rogério de ${ }^{1}$

ASSIS, Rogério de. A Agenda Ecológica e a Palavra De Deus: $O$ que ambas têm a nos dizer? Revista Científica Multidisciplinar Núcleo do Conhecimento. Ano 05, Ed. 01, Vol. 09, pp. 106-116. Janeiro de 2020. ISSN: 2448-0959, Link de acesso: https://www.nucleodoconhecimento.com.br/teologia/agenda-ecologica

\section{RESUMO}

O presente artigo tem por objetivo apresentar a agenda bíblica imbricada com a agenda ecológica. Como metodologia, fora utilizada fontes primárias e secundárias, tais como a Sagrada Escritura e alguns Padres da Igreja, além de outras pesquisas relacionadas ao tema. Como conclusão, observou-se que ambas as agendas têm muito mais elementos em comum do que se pensa ter num primeiro momento.

Palavras Chave: Teologia Bíblica, ecologia, interligação.

\section{INTRODUÇÃO}

Aplauda o mar com todo ser que nele vive, o mundo inteiro e toda gente. As montanhas e os rios batam palmas e exultem de alegria.

Salmo 97

\footnotetext{
${ }^{1}$ Mestrado em Educação; Pós-graduação Lato Sensu em Formação de Docentes para o Ensino Superior; Pós-graduação Lato Sensu em Teologia Reformada; Graduação em Teologia; Graduação em Teologia Anglicana.
} 
Teria a agenda bíblica e a agenda ecológica algo em comum a nos dizer? Não seria a agenda bíblica, ou seja, o manual de como devemos viver a nossa fé algo dissociado da agenda ecológica? Essa não seria apenas responsabilidade dos governos e dos setores responsáveis pelo meio ambiente? A nós cristãos, não basta somente praticar a nossa religião, participar ativamente de uma comunidade de fé, e ao mesmo tempo nos mantermos em dia com as nossas orações? Essas e outras questões norteiam o presente artigo.

Pois bem, constata-se infelizmente que algumas igrejas e/ou ministros religiosos têm sofrido críticas por adotarem a agenda ecológica dos "dias atuais", como se religião fosse apenas algo relacionado à esfera da espiritualidade, algo no estilo "eu e Deus" apenas. Porém, o presente artigo tem a pretensão de abordar a temática e a sua relação com a Palavra de Deus, esclarecendo desse modo que, muito mais do que se pensa, a "agenda ecológica" na verdade está intimamente imbricada com o que podemos chamar de "agenda bíblica", ou seja, ambas falam claramente sobre o cuidado que devemos ter para com a nossa casa comum, esse planeta frágil que é o nosso lar, ou como alguns dizem: "que ainda é o nosso lar, pois estamos destruindo a nossa casa."

\section{DESENVOLVIMENTO}

Como não cuidar da criação, como não cuidar da nossa casa, do nosso planeta que recebemos como um presente de Deus? Tal crítica mencionada na introdução aos que adotam a agenda ecológica em sua práxis, ou seja, no seu "modus procedendl" têm algum sentido? Definitivamente não, de acordo com a nossa pesquisa. Penso que mereçam tais críticas os religiosos que ainda não adotaram a agenda ecológica imbricada com a agenda bíblica, afinal, Deus se revelou a nós não apenas como sendo um Deus Transcendente, mas também como sendo um Deus Imanente, ou seja, que está presente em sua criação. Tal fato, como se sabe é narrado em diversos versículos das Sagradas Escrituras, tanto do Antigo, quanto do Novo Testamento, como por exemplo em Salmos 104: 29,30 
Escondes o teu rosto, e ficam perturbados; se Ihes tiras o fôlego, morrem, e voltam para 0 seu pó. Envias o teu Espírito, e são criados, e assim renovas a face da terra.

E ainda em Provérbios 8:22-31

O Senhor me possuiu no princípio de seus caminhos, desde então, e antes de suas obras. Desde a eternidade fui ungida, desde o princípio, antes do começo da terra.

Quando ainda não havia abismos, fui gerada, quando ainda não havia fontes carregadas de águas. Antes que os montes se houvessem assentado, antes dos outeiros, eu fui gerada. Ainda ele não tinha feito a terra, nem os campos, nem o princípio do pó do

mundo.

Quando ele preparava os céus, aí estava eu, quando traçava o horizonte sobre a face do abismo; Quando firmava as nuvens acima, quando fortificava as fontes do abismo,

Quando fixava ao mar o seu termo, para que as águas não traspassassem o seu mando, quando compunha os fundamentos da terra.

Então eu estava com ele, e era seu arquiteto; era cada dia as suas delícias, alegrando-me perante ele em todo 0 tempo; Regozijando-me no seu mundo habitável e enchendo-me de prazer com os filhos dos homens.

Deus se alegrou com a sua criação e a realizou para que nela tenhamos vida e vida em abundância. "Deus viu que tudo era bom" (Gn 1, 31). O Criador tudo planejou de modo perfeito para que os seres criados pudessem habitar e se deliciar de tudo o que fora criado. Contudo, infelizmente, a história mostra claramente que os seres criados ainda não entenderam que devem cuidar do seu habitat natural como um presente 
recebido do Criador. E como todo presente que recebemos, se dele não cuidarmos, ele se acabará. Nesse sentido, um sentimento de saudade relacionado ao "paraíso perdido" deve fazer parte da vida do crente, ou seja, justamente, por crermos no Deus da aliança e da promessa, e por isso mesmo, saber que o mundo como está não está de acordo com a promessa feita pelo Criador de um novo céu e uma nova terra, é que devemos nos empenhar para que o nosso mundo seja melhor. Lemos em (Ap 21, 1 4):

Depois vi um novo céu e uma nova terra. O primeiro céu e a primeira terra tinham desaparecido e o mar já não existia mais. ${ }^{2}$ Vi também a cidade santa, a nova Jerusalém, que descia do céu, da parte de Deus. Ela estava vestida como uma noiva enfeitada para o seu marido. ${ }^{3}$ Então ouvi uma voz forte que vinha do trono, dizendo:

Agora, a morada de Deus vai ser com os homens. Deus habitará com eles e eles serão povos de Deus. Então, o próprio Deus estará com eles e Ele Ihes será por Deus. ${ }^{4}$ Deus enxugará todas as lágrimas de seus olhos e a morte já não existirá mais. Não haverá mais luto, nem choro e nem dor, porque as coisas velhas já passaram.

Tal promessa de um novo céu e uma nova terra pode levar a muitos de nós a uma certa acomodação quanto ao cuidado com a nossa casa, afinal, muitos pensam: se Deus prometeu o melhor, se esta promessa se trata de uma questão escatológica, ou seja, algo que está por fim no final dos tempos, não basta esperarmos passivamente pela realização da promessa? De acordo com o teólogo da esperança, Jüngen Moltmann, que nos apresenta um novo conceito da escatologia, não se tratar de uma "pura espera" ou ainda de uma "espera vã", pois, de acordo com a sua teologia, a realidade é pura escatologia, e esta, idêntica à esperança cristã. Esta esperança não apenas abarca tudo aquilo que esperamos, mas também o próprio ato de esperar. Para ele, "O Cristianismo é total e visceralmente escatologia, e não só a modo de apêndice; ele é perspectiva e tendência para frente, e por isso mesmo, renovação e transformação do presente" (Moltmann, 1971, p. 2). 
Ainda segundo Moltmann, a esperança do evangelho tem relação polêmica e libertadora não só com as religiões e ideologias dos homens, mas sobretudo com a vida real e prática dos homens e as circunstâncias em que se leva esta vida. (Moltmann, 1971, p. 395).

A partir dessa nova visão de mundo, dessa nova compreensão da escatologia, entendemos que é preciso muito mais esforços ecológicos, pessoal e globalmente falando do que se têm observado. Realmente trabalhar duro para que a nossa casa seja na medida do possível um lugar melhor para nós, mas sobretudo, para as próximas gerações viverem, em outras palavras, trata-se de um esperançar, ou ainda de uma espera ativa, "Porque sabemos que toda a criação geme e está juntamente com dores de parto até agora. " $(\mathrm{Rm} 8,22)$.

O Criador está presente na sua criação, porém, muitos ainda não entenderam a dialética da transcendência e da imanência divina e acabam por chegar a um certo exagero de compreensão, a) cultivando uma espiritualidade desencarnada e b) "endeusando" a natureza, ou seja, divinizando o que não é divino. Aprofundemos a compreensão. $O$ fato de entender que o Criador está presente na sua criação, não significa entender que "tudo é Deus", que a árvore é Deus, que a lua, o sol e as estrelas são deuses, etc. Tal compreensão, além de para nós cristãos tratar-se de paganismo, também seria panteísmo, portanto, uma visão incorreta do ponto de vista judaicocristão. A teologia cristã ao falar da presença do Criador na sua criação, fala de panenteísmo[2]. Conforme se lê em Gênesis 1,1ss "No princípio, criou Deus os céus e a terra. A terra, porém, estava sem forma e vazia; havia trevas sobre a face do abismo, e o Espírito de Deus pairava por sobre as águas. " Deus ama a sua criação e quer que dela cuidemos. Deus está sempre do lado das possibilidades criadoras e não destruidoras.

Avançando um pouco mais, para nós cristãos, Deus se revelou como Trindade. O Pai, o Filho e o Espírito Santo estavam presentes na Criação em uma linda dança, o que chamamos de pericórese divina. E é em Cristo e por Cristo que todas as coisas foram feitas, e é em Cristo que toda a criação será restaurada. Sendo Deus, Cristo é também Criador. Ele não é criatura, mas sempre existia desde o princípio (João 1:1). Ele é 
chamado "primogênito" porque "nele foram criadas todas as coisas" (Colossenses 1:16). O ponto é que Cristo é superior a qualquer criatura, seja homem, animal, ou ser celeste. Cristo é o porquê da criação - "Tudo foi feito por meio dele e para ele" (1:16). Sem Cristo, nada poderia subsistir (Colossenses 1:17; Hebreus 1:3). Tudo foi criado nele e em direção dele.

Na concepção trinitária da criação, a ideia do Cristo cósmico se relaciona com a ideia do Espírito cósmico presente como força criadora (Jo 3, 5; 2Cor 5, 17) e a experiência de comunhão do Espírito nos limites, sociais e religiosos e ao futuro da nova criação. Sendo o Espírito presença imanente de Deus no mundo, então é possível falar de uma kénosis do Espírito. Aqui se parte do pressuposto de uma ligação entre encarnação do logos e habitação do Espírito. Na tentativa de evitar um panteísmo do Espírito no mundo, toma-se a ideia de $\mathrm{H}$. Heine que, rejeitando o panteísmo, afirmou que Deus está em tudo, mas tudo não é Deus, apontando, desta forma, para a diferença entre panteísmo e pan-enteísmo. Contudo, o panenteísmo diferenciado não consegue conectar a imanência de Deus no mundo com a sua transcendência do mundo; o que é possível à doutrina trinitária da criação no Espírito e do Espírito criador que habita na criação.[3]

Nesse sentido, surge um outro conceito que não pode deixar de ser abordado em nossa reflexão sobre o cuidado para com a criação: a Mordomia Cristã. Contudo, te convido a pensar de forma mais ampla com relação à Mordomia Cristã, afinal, não são apenas os cristãos os que habitam neste planeta. Todos nós enfim, somos convidados a exercermos a nossa mordomia, especialmente claro, os que conhecem a Palavra de Deus. E o que vem a ser a Mordomia? Conforme é sabido, nada mais é do que em primeiro lugar o reconhecimento que Deus é o Senhor de tudo o que fora criado, e, em segundo lugar, nada mais é do que o reconhecimento da nossa responsabilidade de seres criados à sua imagem e semelhança de bem administrarmos os bens que recebemos de graça de suas divinas mãos. Como temos administrado a nossa casa? Eis a grande questão. 
Deus nos constituiu como mordomos de toda a sua criação (SI 115.16). Sendo Ele mesmo o Senhor de tudo (SI 24.1). Confiou aos homens o domínio de suas obras (Gn 1.26). Contudo, requer que cada um exerça a mordomia com fidelidade (I Co 4.2). Ciente que um dia prestaremos conta a Deus por tudo que fizemos. (Rm 14.12; II Co 5.10).

Recorrendo agora a um dos pais da igreja, no que tange à interligação entre Fé e da Razão, lemos em John Wesley que... outro princípio fundamental no estudo da Bíblia, para Wesley, é a razão. Num dos seus livros, ele diz: "Quem renuncia a razão, renuncia a religião; a religião e a razão andam de mãos dadas; toda religião irracional é falsa" (Obras, XIV, 254).[4]

Em Sermões, 33, ele mostra possuir conhecimentos dos problemas políticos do mundo, ao dizer:"... e não só os espanhóis e os portugueses, massacrando milhares na América do Sul...". Na verdade, ele era sensível às dificuldades enfrentadas pelos ingleses da classe pobre. Em outro de seus escritos, ele questiona: "Por que o cereal (pão) está tão caro"? A seguir, ele analisa a situação. O pão está caro, porque o cereal está sendo usado para fazer bebida e para alimentar os cavalos das pessoas ricas (Obras 11. págs. 53-59). Os escritos deixados por Wesley formam um precioso documentário sobre a situação econômica, social, política e religiosa, especialmente da Inglaterra do século XVIII.[5]

Pois bem, inúmeras pesquisas feitas pelos principais organismos internacionais com relação ao meio ambiente, nos fornecem os tristes números relacionados aos desmatamentos, ao degelo das calotas polares, às inúmeras mortes dos animais, inclusive ameaçados de extinção devido ao aquecimento dos oceanos, e claro, mostram também os números extremamente preocupantes da morte do próprio ser humano, que têm sofrido fome, doenças e tantas outras misérias causadas pelo egoísmo humano. Penso ser inequívoco, portanto, a constatação de que não estamos exercendo bem a nossa mordomia cristã. Nesse sentido, é nosso dever como igrejas, como comunidades locais de fé cobrar das autoridades devidamente constituídas para que bem administrem os bens naturais que são comuns a tudo o que vive, afinal, qual é a nossa missão neste mundo? Sermos "sal da terra e luz do mundo" (Mateus 5, 13- 
14). O que estamos fazendo com a sua criação é inequivocamente responsabilidade nossa e, claro, estamos sofrendo as consequências de nossas más atitudes, tanto no nível pessoal, quanto coletivo, afinal, não adianta cobrar dos outros se também nós jogamos plásticos nos oceanos e não temos o menor cuidado com o consumo responsável, etc.

Nesse sentido, te convido a pensar em duas palavras: Globalização e Planetarização. A primeira, mais conhecida por muitos de nós, como sabemos, está relacionada à questão mercadológica e social e fala das relações que os mais variados países têm entre si do ponto de vista do livre comércio. Convido-os, porém, a substituírem a palavra globalização pela palavra "planetarização". Tal expressão, além de no meu ponto de vista ser muito mais cristã, fala-nos muito mais com relação ao cuidado que devemos ter para com a nossa casa comum, ou seja, nosso planeta que tanto tem sido explorado em seus recursos naturais e, infelizmente de forma não sustentável.

Sim, é preciso respeitarmos o descanso da terra. E aqui temos mais uma chave de interligação: o descanso do Criador no sábado com o descanso da terra, pois, do mesmo modo como o Criador descansou após tudo ter criado e ver que tudo era bom, também a terra precisa descansar para que naturalmente possa respirar e se preparar para a nova etapa produtiva, ou seja, para a nova criação que nos remete à Ressurreição. $O$ descanso é algo consagrado pelo Criador.

A ideia do sábado como conclusão da criação, e como revelação da existência repousante de Deus em sua criação, acena para além do sábado; aponta para um futuro no qual criação e revelação de Deus se tornam redenção entendida como o sábado eterno e nova criação. Porém, o ano sabático (Lv 25, 1-7), e o ano jubilar (Lv 25, 8-55) e a visão profética do ano messiânico (Is 61, 1-11), estão interligados e apontam para além do tempo histórico, isto é, para o tempo messiânico. No final dos tempos, o sábado se transformará, numa festa sem fim. Propõe-se, aqui, interligar o sábado ao Domingo, ao dia da ressurreição de Cristo, o dia do Senhor, o que antecipa não só o descanso sabático do final do tempo, mas o início da nova criação. O sábado permite participar do 
descanso de Deus, a festa da ressurreição permite participar da força na re-criação do mundo. Este dia é pensado como o primeiro dia da semana. (lbid,. 1).

Teria Santo Agostinho, um dos padres da Igreja mais lidos e conhecidos, ele que vai influenciar o pensamento de tantos reformadores, algo a nos dizer sobre o presente assunto? Sim, ele tem algo a nos dizer. Lemos em sua obra Cidade de Deus:

O amor de si levado até o desprezo de Deus gera a cidade terrena; o amor de Deus levado até o desprezo de si gera a cidade celeste. Aquela aspira à glória dos homens, esta põe acima de tudo a glória de Deus. . . . Os cidadãos da cidade terrena são dominados por uma estúpida ambição de predomínio que os induz a subjugar os outros; os cidadãos da cidade celeste se oferecem um ao outro em serviço e espírito de caridade e respeitam docilmente os deveres da disciplina social.[6]

A partir dessa breve citação, fica evidente que é por conta do nosso orgulho, ou ainda, usando as palavras de Santo Agostinho, por conta de "uma estúpida ambição" que nós estamos procedendo mal, contudo, fica o convite à mudança de comportamento, afinal, nunca é tarde para que procedamos como cidadãos da cidade celeste, ou seja, de forma diferente, responsável, e que observa os deverem sociais além dos religiosos, afinal, ambos estão imbricados.

\section{CONCLUSÃO}

O presente artigo teve a pretensão de responder ao seguinte problema: A Palavra de Deus e a Agenda Ecológica: O que ambas têm a nos dizer?

Partimos da hipótese de que ambas as agendas estão imbricadas, portanto, elas têm algo em comum a nos dizer, o que fomos comprovando ao longo do artigo. Para isso nos utilizamos de algumas fontes primárias e secundárias, tais como a própria Palavra de Deus, citando também alguns poucos padres da igreja, além de pesquisas relacionadas com o tema. 
Temos esperança de ter conseguido demonstrar a interligação entre as duas agendas, ou seja, em nossa leitura, não é possível cultivar apenas uma espiritualidade desencarnada, seria como fecharmos os olhos para os problemas de nossa sociedade, do nosso planeta, e tal fato do ponto de vista teológico seria contrário à própria fé cristã.

Por fim, fica o desafio a cada um de nós de fazermos uso desse instrumental teológico e de muitos outros, com vistas ao avivamento ainda maior de nós mesmos e de nossas comunidades locais, ciosos do nosso mister de mordomos da criação, a fim de que esperançando transformemos este mundo num lugar melhor para nós e, sobretudo, para as gerações vindouras, nossos filhos, netos e demais gerações viverem.

\section{REFERÊNCIAS}

FREIRE DA SILVA, Maria. A Criação e a Questão Ecológica no Pensamento de Jürgen Moltmann. Disponível em: <https://www.maxwell.vrac.pucrio.br/21630/21630.PDF>. Acesso em 24 nov. 2019.

MOLTMANN, Jürgen. Teologia da esperança: estudos sobre os fundamentos e as consequências de uma escatologia cristã. São Paulo: Herder, 1971.

MAZZAROLO, Isidoro. A Bíblia e o meio ambiente. Disponível em: <http://www.fsma.edu.br/visoes/ed05/ed05_artigo_7.pdf>. Acesso em 23 nov. 2019.

RAIMER, Haroldo. Hermenêutica ecológica de textos bíblicos. Disponível em: <https://www.abiblia.org/ver.php?id=1259>. Acesso em 24 nov. 2019.

\section{APÊNDICE - REFERÊNCIAS DE NOTA DE RODAPÉ}

2. Deus está presente no cosmos e o cosmos está presente em Deus. A teologia antiga expressava esta mútua interpenetração pelo conceito "pericórese", aplicada às relações entre Deus e a criação e depois entre as divinas Pessoas da Trindade. A teologia moderna cunhou outra expressão, o "panenteísmo" ( em grego: $p a n=t u d o ; e n=e m$; theos=Deus). Quer dizer: Deus está em tudo e tudo está 
em Deus. Esta palavra foi proposta pelo evangélico Frederick Krause (1781-1832), fascinado pelo fulgor divino do universo. Disponível em: < http://www.ihu.unisinos.br/noticias/508499-panteismoversuspanenteismo>. Acesso em 26 nov. 2019.

3. https://www.maxwell.vrac.puc-rio.br/21630/21630.PDF

4. Disponível em: <file://C:/Users/Rog\%C3\%A9rio/Downloads/2299-5564-1PB\%20(1).pdf>. Acesso em: 26 nov. 2019.

5. (Ibid,. 3).

6. Disponível em: <http://oestadodaarte.com.br/a-cidade-de-deus-de-agostinho/> Acesso em 26 nov. 2019.

Enviado: Novembro, 2019.

Aprovado: Janeiro, 2020. 